\title{
Dual Band Notched UWB MIMO Antenna for Surfaces Penetrating Application
}

\author{
Abdelhalim Chaabane ${ }^{1}$, Abdesselam Babouri ${ }^{2}$ \\ ${ }^{1}$ Laboratoire des Télécommunications-LT, Université 8 Mai 1945 Guelma, BP 401, Guelma 24000, Algeria \\ ${ }^{2}$ Laboratoire de Génie Électrique de Guelma-LGEG, Université 8 Mai 1945 Guelma, BP 401, Guelma 24000, Algeria \\ *corresponding author, E-mail: abdelhalim. chaabane@univ-guelma.dz
}

\begin{abstract}
This paper introduces a novel compact planar UltraWideband (UWB) Multiple-Input-Multiple-Output (MIMO) antenna with a dual-band notched performance for wireless communication systems application with Surfaces Penetrating (SP) capability. To avoid the interference from co-existing systems, two notched bands are introduced by including two symmetrical strips and three linked equal radius circles inside the radiating patches. The two ports MIMO antenna is printed on the low-cost FR4 substrate with a compact size of $0.293 \lambda_{0} \times 0.17 \lambda_{0} \times 0.008 \lambda_{0}$ at 1.57 GHz. The measured results indicate that the $-10 \mathrm{~dB}$ bandwidth of the proposed MIMO antenna covers a wide bandwidth $1.57-12.4 \mathrm{GHz}(155.05 \%)$ with a dual-band rejection from $2.04 \mathrm{GHz}$ to $3.98 \mathrm{GHz}$ and from $4.8 \mathrm{GHz}$ to $6.22 \mathrm{GHz}$. The effects of numerous construction and decoration surfaces on the antenna's reflection coefficients are measured. Gypsum, White Portland Cement, Slate, Marble, Wood and Reinforced Concrete is tested. A good penetrating capability is measured which confirms the aptitude of the proposed MIMO antenna to work as SP antenna.
\end{abstract}

\section{Introduction}

The Ultra-Wideband (UWB) wireless communication systems have received a widespread attention due to its improved performances in a large frequency range with a minimum power level [1]. Furthermore, the rise requirement of the wireless channel capacity extension and the high data rates for an acceptable range necessitate thinking for new technologies with good performances [2].

Multiple-Input-Multiple-Output (MIMO) technology, that exploits multiple antennas both in the transmitting and receiving devices, plays a significant role in modern UWB systems due to its specific advantages principally for conquering the multipath fading effect and for rising the transmission capacity [3-5]. One of the serious defy of UWB systems is the frequency interference with other co-existing narrowband wireless communication systems such as the WiMAX operating in the $3.3-3.8 \mathrm{GHz}$ band and the WLAN operating between $2.4-2.484 \mathrm{GHz}$ for the lower band and between $5.15-5.825 \mathrm{GHz}$ for the upper band. For that reason, UWB MIMO antenna with bands rejected performance is desired [7, 8]. Recently, many UWB MIMO antennas with bands notched function have been discussed
[9-14], but there are no realistic environmental tests for these antennas.

The Surfaces Penetrating (SP) capability is considered for a variety of applications including environmental and civil engineering applications [15]. For all SP systems, antennas are the indispensable components that determine the performances of the system [16]. The varieties and the requirements of the SP application have attracted more interest to design new systems with efficient antennas [17]. Until now, several types of antennas have appeared in the literature for various SP applications such as those in [1825].

A double exponentially tapered slot antenna that has a big volume of $258 \times 210 \times 1.5 \mathrm{~mm}^{3}$ and operates in the frequency range $0.22-6 \mathrm{GHz}$ has been proposed in [18] for SP detection of a bury target. The same type of antenna with the same inconvenience of size has been investigated in [19] for a SP application. However, no more than $2.1 \mathrm{GHz}$ impedance bandwidth with a lower frequency of $1.4 \mathrm{GHz}$ has been achieved. Presenting the same drawback of the narrow bandwidth between $250 \mathrm{MHz}$ and $750 \mathrm{MHz}$, a bowtie antenna that has a huge structure of about $180 \times 300$ $\mathrm{mm}^{2}$ has been proposed in [20] for SP system. While an excellent penetration depth with a high resolution can be achieved mostly by using SP systems with wideband antennas [21]. In [22] a tapered TEM horn antenna covering a wide frequency range $0.83-12.8 \mathrm{GHz}$ has been investigated for the Asphalts Pavement, however its voluminous size of $178 \times 140 \times 251 \mathrm{~mm}^{3}$ is the major constraint which can be awkward in some applications. In [23] a single port umbrella shaped UWB antenna with a size of $35 \times 30 \times 0.8 \mathrm{~mm}^{3}$ has been tested in a closed proximity of Sandy Soil for ground coupling applications. In [24] a single port leaf-shaped UWB antenna has been proposed for SP application; the antenna has been tested only in a closed proximity of Soil. The similar antenna with a triple-notched band performance has been tested in a closed proximity of Sand, Wood, and Glass in [25]. The same FSS layers have been investigated on the same type of antenna in [26-28] for the ground penetrating purpose; the bed test has consisted basically of sand and wood in [26] and of sand in [27, 28]. However, choosing other surfaces for the test is a great necessity. We will have to design antennas according to the existing construction and decoration materials, or to choose the appropriate materials depending on the existing systems and on the job that we want to exercise inside. 
A compact coplanar waveguide fed dual-band notched UWB MIMO antenna for wireless communication systems application with SP capability is introduced in this paper. The proposed antenna covers a wide bandwidth 1.57-12.4 $\mathrm{GHz}$ with a dual-band rejection performance from 2.04 $\mathrm{GHz}$ to $3.98 \mathrm{GHz}$ and from $4.8 \mathrm{GHz}$ to $6.22 \mathrm{GHz}$ to avoid the interference with the co-existing systems. The two notched bands are achieved by introducing two symmetrical strips and three linked equal radius circles inside the radiating patches. All the designs are firstly achieved by employing the commercial software packages CST Microwave Studio $^{\mathrm{TM}}$ version 2016 [29]. To demonstrate the effectiveness of the proposed antenna for the SP application, the effects of numerous construction and decoration materials on the antenna's reflection coefficients are measured. Gypsum, White Portland Cement, Slate, Marble, Wood and Reinforced Concrete are tested in this paper.

\section{Configuration and analysis of the antenna with a single port}

The configuration of the proposed antenna with a single radiating element is presented in the Figure 1. The antenna is designed using the low-cost FR4 epoxy substrate (relative dielectric constant of 4.4 and a loss tangent of 0.025 ), with a size of $0.17 \lambda_{0} \times 0.139 \lambda_{0} \times 0.008 \lambda_{0}$ at $1.57 \mathrm{GHz}$. The radiating element consists of a modified open annular shape. A corrugated geometry is applied at the outer edge of the radiating element by using a successive subtraction then addition of half circles as shown in the Figure 1(a). The influence of the radius $r_{4}$ of these half circles on the reflection coefficient of the UWB antenna is presented in the Figure 2, an optimized radius $r_{4}=0.51 \mathrm{~mm}$ is used. In addition, the metal is removed from the top part of the radiating circular ring characterized by a low concentration current distribution. Consequently, a lighter weight can be obtained which is especially enviable from the miniaturization viewpoint. Further degrees of flexibility in the design and possibly reduced conductor losses are attained. To achieve the same objectives, two elliptical slots with radius of $\left(r_{2}, r_{3}\right)$ are inserted on the two sides of the ground plane. The inner corners of the ground plane are truncated for adjusting the capacitive and the inductive coupling between the radiating open annular patch and the ground plane. Consequently, a better impedance matching and a larger impedance bandwidth can be obtained. In order to avoid the interference with the co-existing systems, two symmetrical strips and three linked equal radius circles are etched inside the open annular patch. The first notched band centered at $3.5 \mathrm{GHz}$ is achieved by etching two symmetrical strips that act as a single half guided wavelength resonator at the same resonating frequency. Another resonator formed by linking equal radius circles of a total effective length equal to a quarter guided wavelength is placed between the two symmetrical strips to achieve the second notched band centered at $5 \mathrm{GHz}$. Based on the other published works like [30], the frequency center of the two notches can be deduced by the two equations (1) and (2).

$$
\begin{aligned}
& f_{\text {lower notch }} \approx \frac{c}{\lambda_{g} \sqrt{\left(\varepsilon_{r}+1\right) / 2}} \approx \frac{c}{2 L_{T S} \sqrt{\left(\varepsilon_{r}+1\right) / 2}} \\
& f_{\text {upper notch }} \approx \frac{c}{\lambda_{g} \sqrt{\left(\varepsilon_{r}+1\right) / 2}} \approx \frac{c}{4 L_{T C} \sqrt{\left(\varepsilon_{r}+1\right) / 2}}
\end{aligned}
$$

Here $\varepsilon_{r}$ is the dielectric constant of the substrate, $c$ denotes the speed of light in free space, $\lambda_{g}$ is the guided wavelength, $L_{T S}$ is the sum of the total effective length of the two symmetrical strips that is calculated as $L_{T S}=2\left(L_{I}+W_{I}\right)$ where $L_{l}$ and $W_{l}$ are respectively the length and the width of each strip, $L_{T C}$ is the total effective length of the linked circles that is calculated as $L_{T C}=L_{2}+W_{2}$ where $L_{2}$ and $W_{2}$ are respectively the total length of the linked circles and the diameter of each circle.

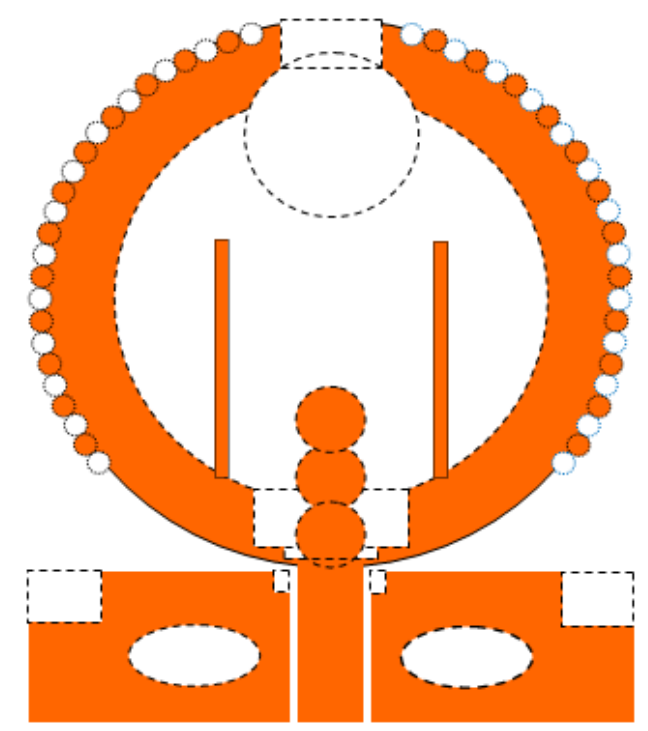

(a)

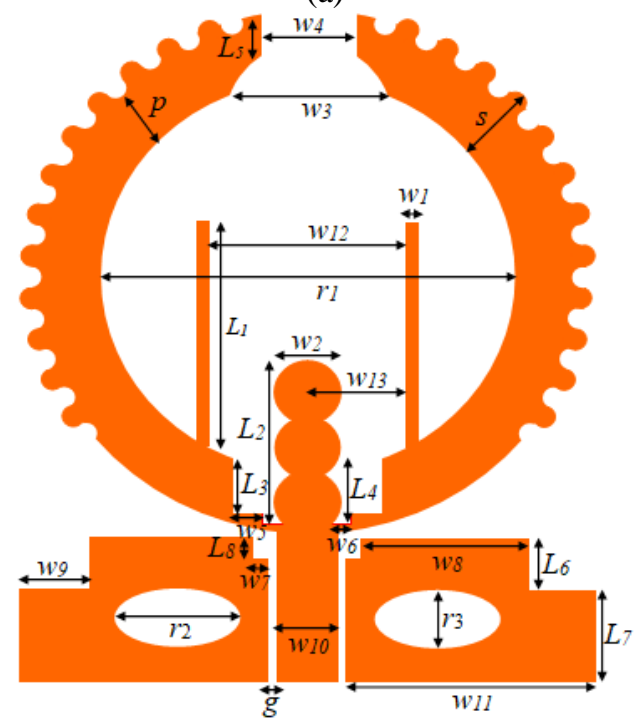

(b)

Figure 1: Proposed dual-band notched UWB antenna with a single element, (a) Construction steps of the antenna, (b) Detailed configuration of the antenna. 
The dimensions of the proposed antenna are optimized to maximaze the frequency bandwidth. All the geometrical dimensions of the proposed UWB antenna (Figure 1(b)) with a single element are as follows:

$L_{1}=11.176 \mathrm{~mm}, L_{2}=7.874 \mathrm{~mm}, w_{1}=0.508 \mathrm{~mm}, w_{2}=1.524$ $\mathrm{mm}, w_{3}=7.62 \mathrm{~mm}, w_{4}=4.064 \mathrm{~mm}, L_{3}=3.556 \mathrm{~mm}, L_{4}=4.064$ $\mathrm{mm}, r_{l}=17.78 \mathrm{~mm}, r_{2}=6.096 \mathrm{~mm}, r_{3}=3.048 \mathrm{~mm}, r_{4}=0.51$ $\mathrm{mm}, L_{5}=1.27 \mathrm{~mm}, L_{6}=2.032 \mathrm{~mm}, L_{7}=5.08 \mathrm{~mm}, L_{8}=0.762$ $\mathrm{mm}, w_{5}=1.27 \mathrm{~mm}, w_{6}=1.016 \mathrm{~mm}, w_{7}=0.508 \mathrm{~mm}, w_{8}=7.874$ $\mathrm{mm}, w_{9}=2.54 \mathrm{~mm}, w_{10}=3.556 \mathrm{~mm}, w_{11}=11.176 \mathrm{~mm}$, $w_{12}=8.64 \mathrm{~mm}, w_{13}=4.32 \mathrm{~mm}, g=0.254 \mathrm{~mm}, s=4.318 \mathrm{~mm}$, $p=3.302 \mathrm{~mm}$.

The influences of the position and the length of the two strips and of the linked circles on the dual-notched band are carried out to show the structures responsible for the bands rejection function. Figure 3(a) shows that a sufficient distance between the two symmetrical strips need to be preserved, an acceptable distance of $w_{12}=8.64 \mathrm{~mm}$ is used in the proposed antenna. In addition, Figure 3(b) shows that if the linked circles shift to one of the two strips, the upper notched band is affected. The three linked circles are placed in the middle (for $w_{13}=4.32 \mathrm{~mm}$ ) between the two symmetrical strips in the proposed antenna.

As depicted in Figure 3(c), the center of the lower rejected band shifts for the low frequency side by escalating the length $L_{1}$ of the two symmetrical strips from $9.906 \mathrm{~mm}$ to $12.446 \mathrm{~mm}$. Besides, tuning this dimension has no effect on the upper notched-band. Figure 3(d) indicates that when the total length $L_{2}$ of the linked circles resonator escalates from $6.223 \mathrm{~mm}$ to $8.89 \mathrm{~mm}$ the center of the upper notched band shifts for the lower frequency side without any effects on the lower rejected band. Thus, the lower notched band width is decided by the two symmetrical strips while the upper notched-band is decided by the linked circles. The current density on the antenna's surface with a single element is useful to show the structures responsible for the production of the two notched bands. High current distributions along the two investigated strips and on the linked circles at $3.75 \mathrm{GHz}$ and $5.25 \mathrm{GHz}$, respectively, are detected.

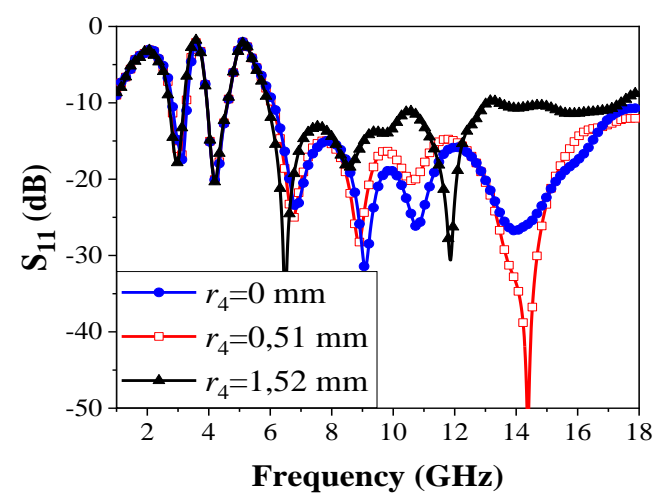

Figure 2: Influence of the radius of the successive half circles used to create the corrugations on the reflection coefficient of the dual-band notched UWB antenna with a single element.

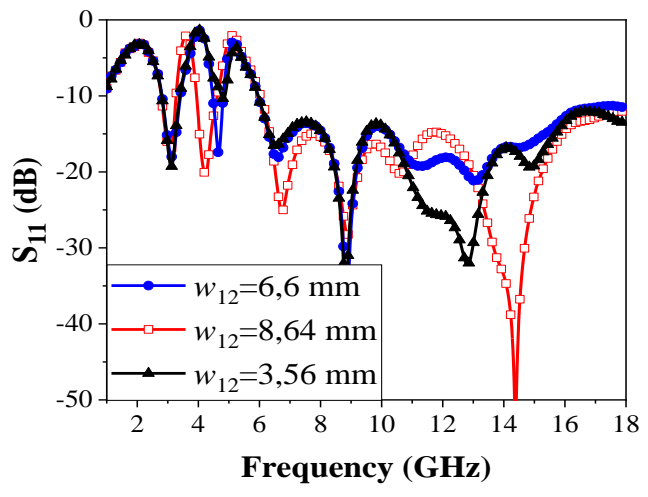

(a)

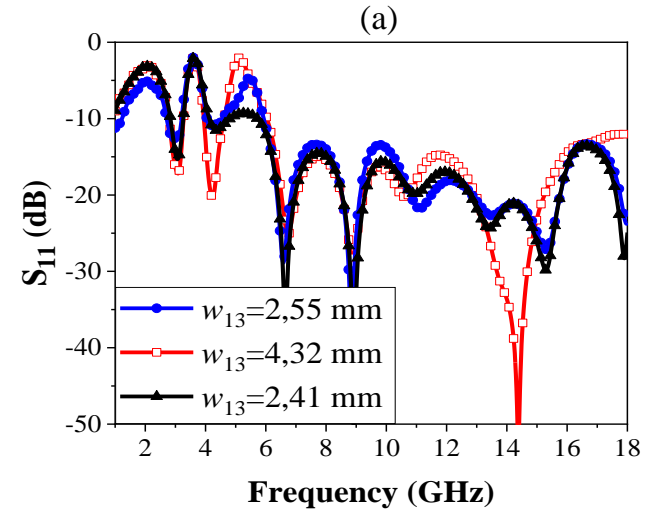

(b)

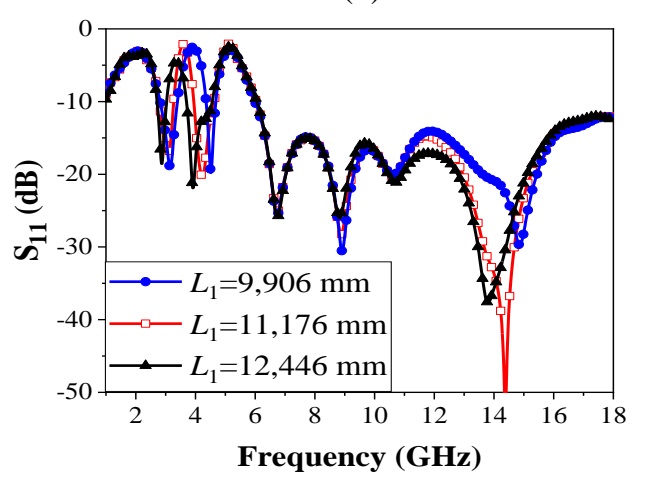

(c)

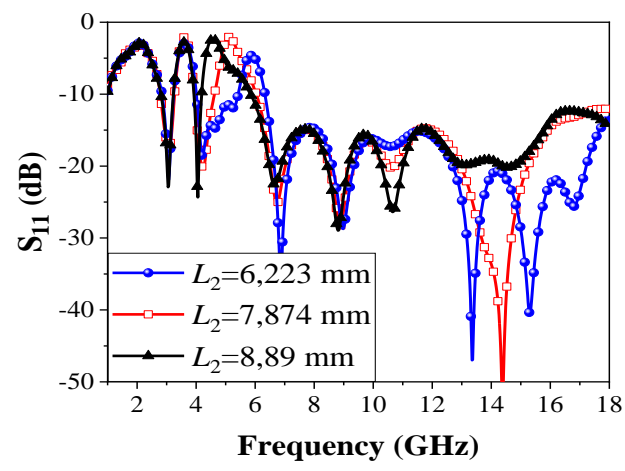

(d)

Figure 3: Influence of the positions and the lengths of the injected parasitic elements on the reflection coefficient of the dual-band notched UWB antenna with a single element, (a) Position of the two symmetrical strips, (b) Position of the linked circles, (c) Length of the two symmetrical strips $\left(\mathrm{L}_{1}\right)$, (d) Length of the linked circles $\left(\mathrm{L}_{2}\right)$. 


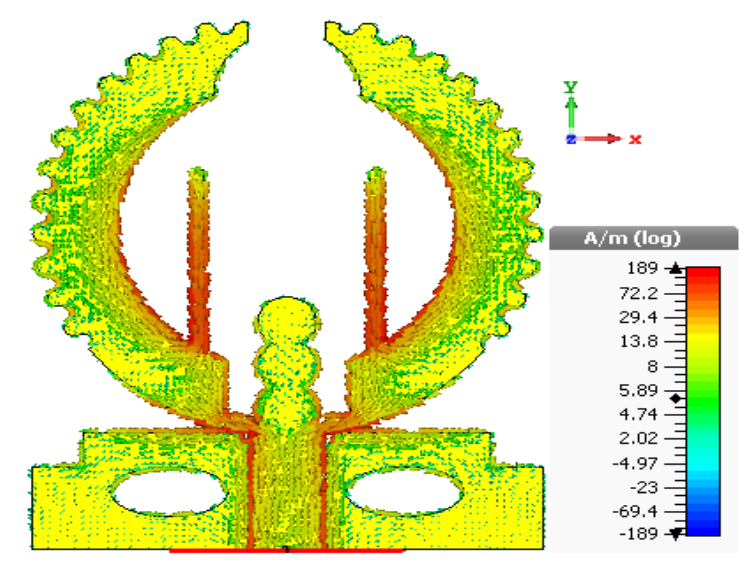

(a)

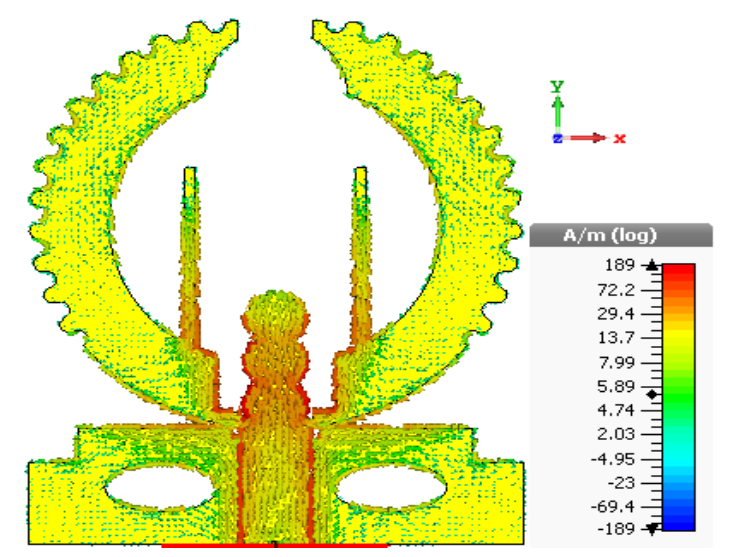

(b)

Figure 4: Current density on the antenna's surface with a single element at the bands notched frequencies at (a) $3.75 \mathrm{GHz}$, (b) 5.25 $\mathrm{GHz}$.

As shown in Figure 4(a), a strong homogeneous current density is found along the two symmetrical strips at 3.75 $\mathrm{GHz}$, the current propagation is deterred and the antenna does not respond. A poor current flowed along the linked circles is observed which indicates a nil contribution of this resonator on the production of the lower notched band. In Figure 4(b) the distributed current at $5.25 \mathrm{GHz}$ is mostly concentrates around the linked circles while the currents along the two symmetrical strips are fairly small, which indicate that the linked circles are the responsible for the generation of the second notched band $5.25 \mathrm{GHz}$, and tuning the dimensions of the two symmetrical strips doesn't influt on the upper notched-band.

\section{Dual-band notched UWB MIMO antenna design}

Figure 5 shows the configuration and a photo of the fabricated prototype MIMO antenna. The two ports MIMO antenna is printed on the FR4 epoxy substrate with overall size of $0.293 \lambda_{0} \times 0.17 \lambda_{0} \times 0.008 \lambda_{0}$ at $1.57 \mathrm{GHz}$. The two radiating elements save the same dimensions of the antenna's radiating element with a single port.

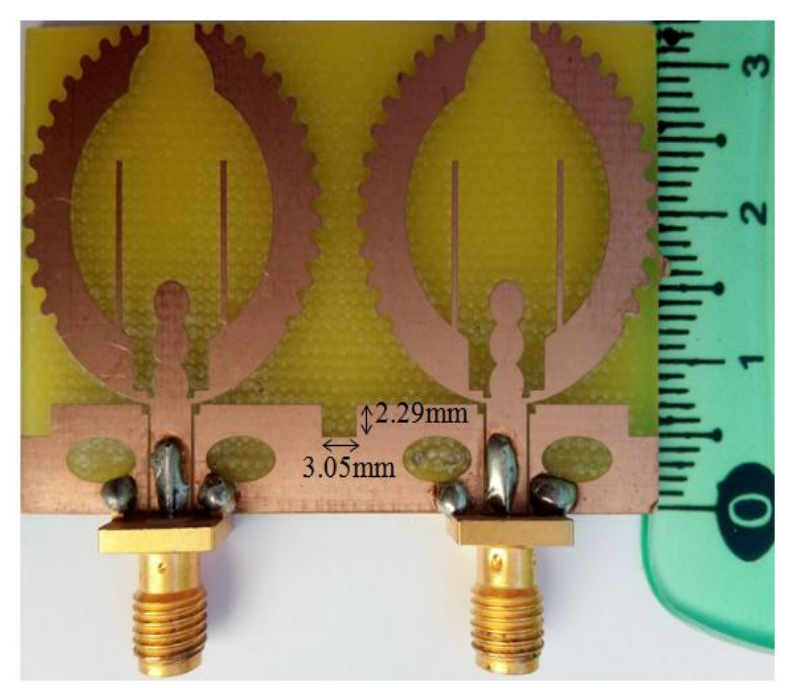

Figure 5: Fabricated prototype of the proposed dual-band notched UWB MIMO antenna.

The S-parameters of the proposed coplanar waveguide fed dual-band notched UWB MIMO antenna are measured using the R\&S@ZNB Vector Network Analyzer. From the experimental results (Figure 6(a)), the $-10 \mathrm{~dB}$ bandwidth of the antenna covers a wide bandwidth $1.57-12.4 \mathrm{GHz}$ (155.05\%) with a dual-band rejected from $2.04 \mathrm{GHz}$ to 3.98 $\mathrm{GHz}$ and from $4.8 \mathrm{GHz}$ to $6.22 \mathrm{GHz}$. Besides, the $\mathrm{S}_{11} / \mathrm{S}_{22}$ parameters are nearly below $-10 \mathrm{~dB}$ in the whole operating bandwidth. In addition, it can be seen that the isolation ports $\mathrm{S}_{12} / \mathrm{S}_{21}$ are nearly below $-10 \mathrm{~dB}$ throughout the entire operating bandwidth (Figure 6(b)), a good agreement between the simulated and the measured results are obtained. As depicted from the measured $S_{12}$ and $S_{21}$ phase responses (Figure 6(c)), linear appearances over the pass frequency band are obtained that signifies a low dispersion. Nonlinear phase responses are detected at the dual-rejected band.

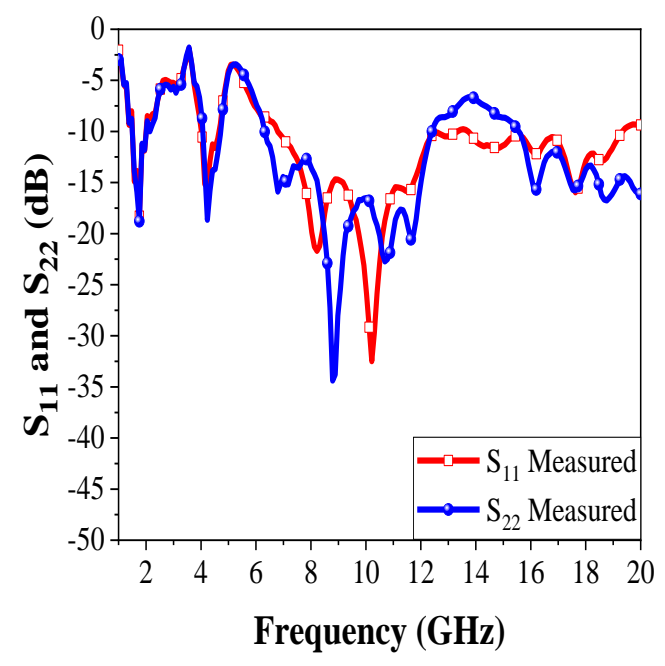

(a) 


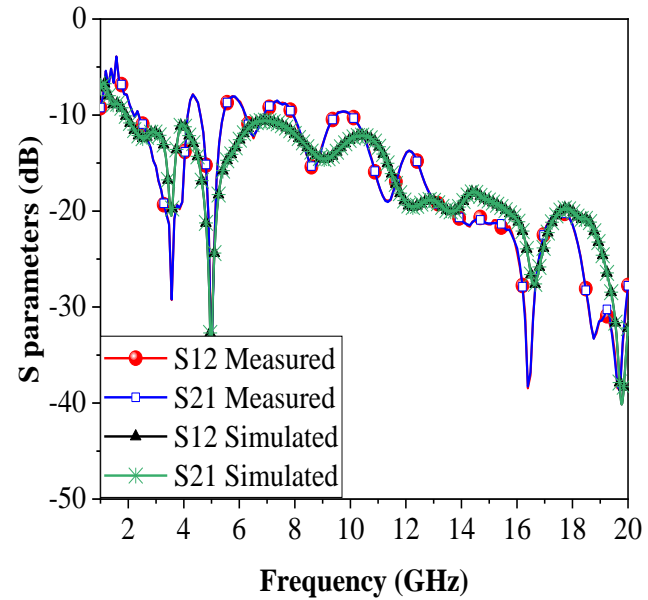

(b)

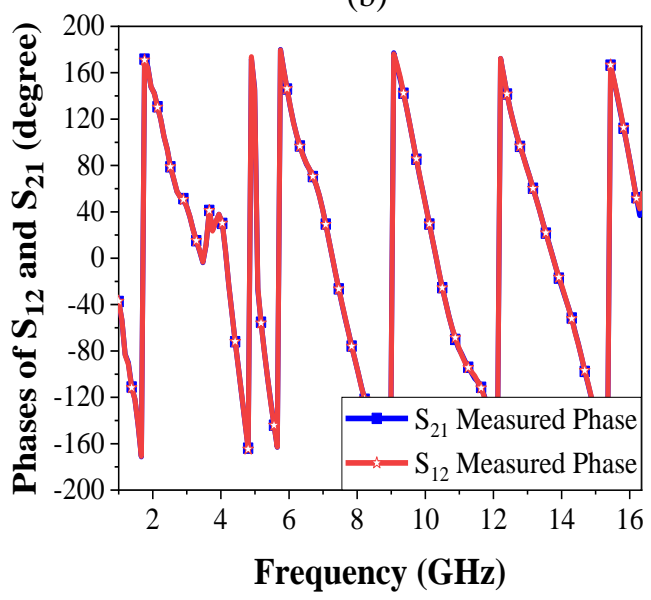

(c)

Figure 6: S-parameters of the proposed dual-band notched UWB MIMO antenna, (a) Measured $\mathrm{S}_{11}$ and $\mathrm{S}_{22}$, (b) Measured and simulated $S_{12}$ and $S_{21}$, (c) Measured phase responses of $S_{12}$ and $S_{21}$.

The simulated normalized co-polarization and crosspolarization radiation patterns for the proposed dual-band notched UWB MIMO antenna in both the $x z$-plane $(\mathrm{H}-$ plane) and the $y z$-plane (E-plane) over various designated frequencies $3.5 \mathrm{GHz}, 5 \mathrm{GHz}, 8.5 \mathrm{GHz}$ and $10.5 \mathrm{GHz}$ are depicted in Figures 7. It is noticed that the co-polarization radiation patterns are nearly omnidirectional over the operating band which are appropriate for the SP application; similar appearances are noted in [31].

As the frequency increases, the radiation patterns undergo a slight deformation compared to those of lower frequencies. The revealed E-plane co-polarization and cross-polarization patterns from Port 2 are mirror image of those from Port 1, along the yz-plane. Besides, the H-plane co-polarization and cross-polarization patterns are almost identical to those from Port 1 due to the evenly shape of the two radiating elements. As depicted in Figure 8 showing the simulated realized gain, except at the notched bands, a consistent gain is achieved that is better than the ones achieved in [32-34].

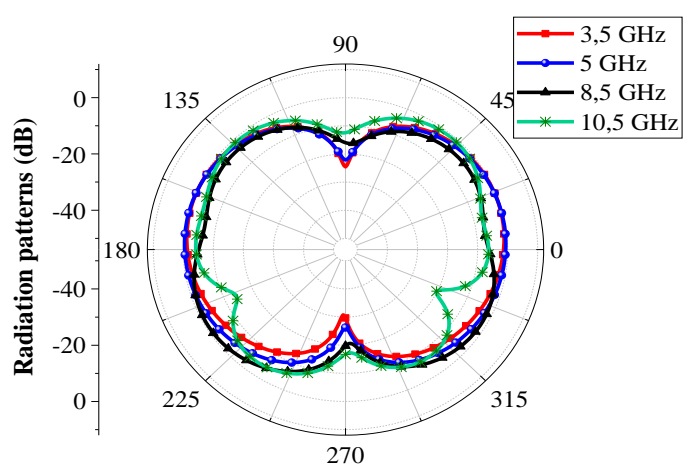

(a)

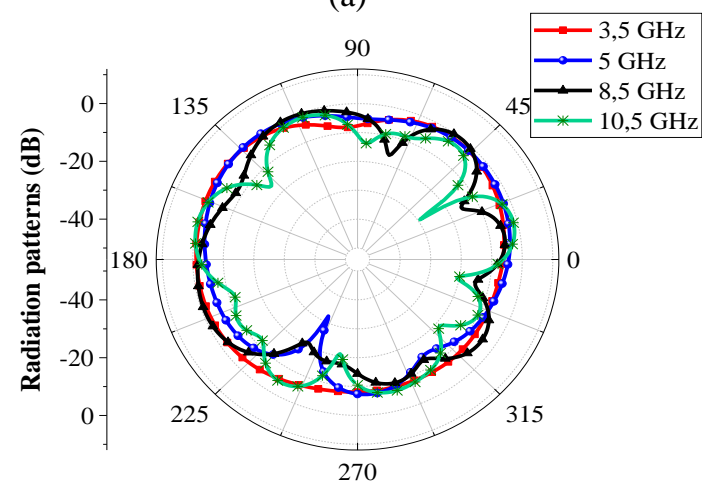

(b)

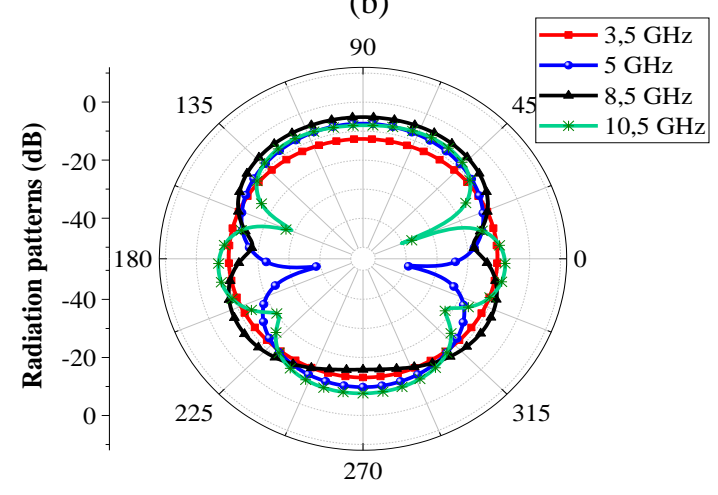

(c)

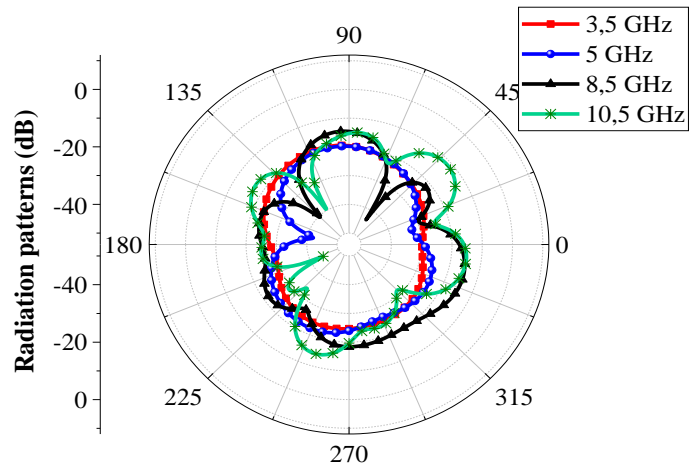

(d)

Figure 7: Normalized radiation patterns at different frequencies from Port 1 , (a) Co-polarization in the $x z$-plane, (b) Co-polarization in the $y z$-plane, (c) Cross-polarization in the $x z$-plane, (d) Cross-polarization in the $y z$-plane. 


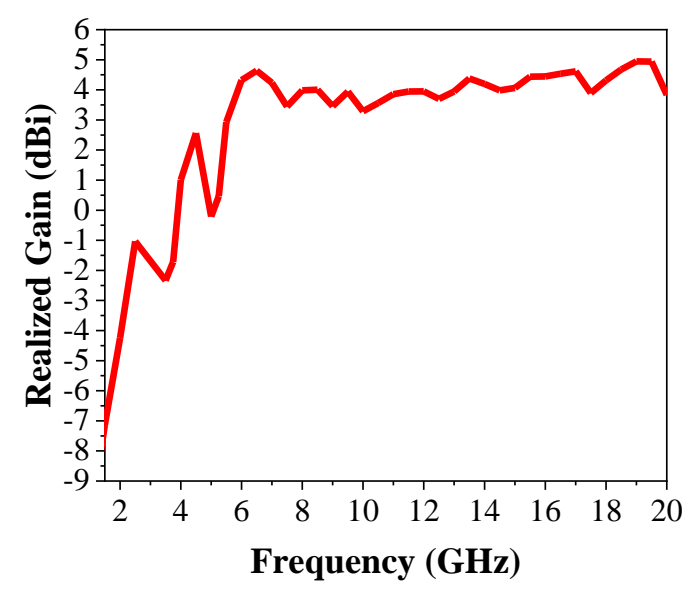

Figure 8: Realized gain achieved by the proposed dual-band notched UWB MIMO antenna.

The diversity performance of the MIMO antenna can be usually estimated by the envelope correlation coefficient ECC and the diversity gain $D G$ parameters. The ECC parameter, which can be calculated in terms of the field radiation patterns of the radiating elements, and the $D G$ parameter are given by the following formulas [35]:

$E C C=\frac{\left|\iint_{4 \pi}\left[\vec{P}_{1}(\theta, \varphi) * \vec{P}_{2}(\theta, \varphi)\right] d \Omega\right|^{2}}{\iint_{4 \pi}\left|\vec{P}_{1}(\theta, \varphi)\right|^{2} d \Omega \iint_{4 \pi}\left|\vec{P}_{2}(\theta, \varphi)\right|^{2} d \Omega}$

$D G=10 \sqrt{1-|E C C|^{2}}$

Here $\vec{P}_{1}$ and $\vec{P}_{2}$ are the field radiation patterns of the two radiating elements, $\Omega$ denotes the solid angle and $*$ is the Hermitian product.

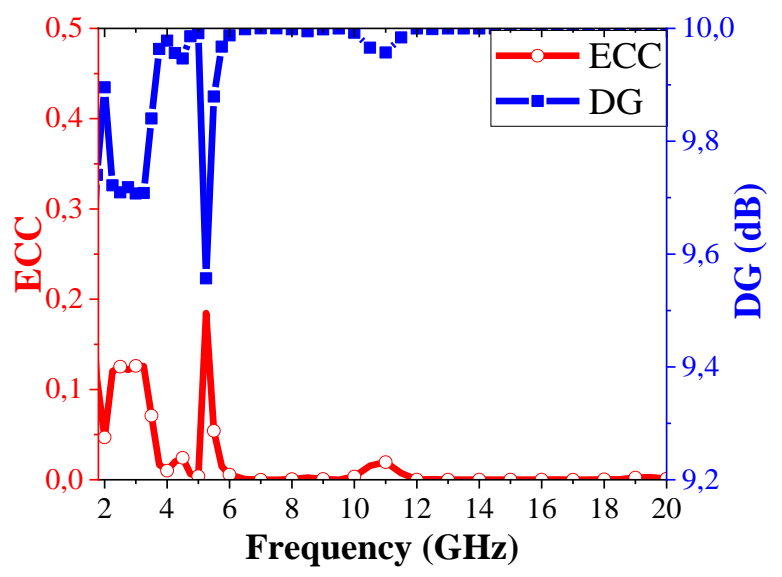

Figure 9: Envelope correlation coefficient and diversity gain performances of the proposed dual-band notched UWB MIMO antenna.
As depicted in the Figure 9, the simulated envelope correlation coefficient (ECC) evaluated from the far-field characteristics of the radiating elements is found less than 0.185 that is well under the usual tolerable value 0.5 . In addition, the simulated diversity gain (DG) is nearly $10 \mathrm{~dB}$ within the considered frequency band $(>9.55 \mathrm{~dB})$, which indicates the good diversity performance is achieved.

\section{Surfaces penetrating test}

In this section, the reflection coefficients of the proposed dual-band notched UWB MIMO antenna are measured by keeping the antenna in touch condition to different realistic environments, as depicted in Figure 10.

Different construction and decoration materials are chosen: Marble, Slate, Reinforced Concrete, Wood, Gypsum and White Portland Cement, Figure 11. The materials: Gypsum, White Portland Cement, Concrete and Reinforced Concrete are tested in solid form and specimens are fabricated by the following sizes and mixed by the subsequent portions:

- Reinforced Concrete $\left(155 \times 122.3 \times 85 \mathrm{~mm}^{3}\right): 2$ portions of grey Portland Cement Powder, 1 portion of white building Sand, 1 portion of yellow building Sand, 1 portion of Water, 2 portions of 9-19 mm crushed Gravel, 5 building Iron rods of $9 \mathrm{~mm}$ diameter,

- Concrete $\left(131.5 \times 110.11 \times 21.48 \mathrm{~mm}^{3}\right): 2$ portions of grey Portland Cement Powder, 1 portion of yellow building Sand, 1 portion of white building Sand, 1 portion of Water, 2 portions of 9-19 mm crushed Gravel, 5 building Iron rods of $6 \mathrm{~mm}$ diameter,

- Gypsum $\left(149.7 \times 103.2 \times 127.75 \mathrm{~mm}^{3}\right)$ : 2 portions of Gypsum Powder, 0.8 portion of Water,

- White Portland Cement $\left(145.2 \times 101.3 \times 119.7 \mathrm{~mm}^{3}\right)$ : 2 portions of white Portland Cement Powder, 1 portion of Water.

The thickness of each tested specimen is as follow: Marble $\left(h_{m}\right)=89.9 \mathrm{~mm}$, Slate $\left(h_{s}\right)=95.7 \mathrm{~mm}$, Concrete $\left(h_{r c}\right)=21.48$ $\mathrm{mm}$, Reinforced Concrete $\left(h_{r c}\right)=85 \mathrm{~mm}$, Gypsum $\left(h_{G}\right)=127.7 \mathrm{~mm}$, White Portland Cement $\left(h_{w c}\right)=119.7 \mathrm{~mm}$.

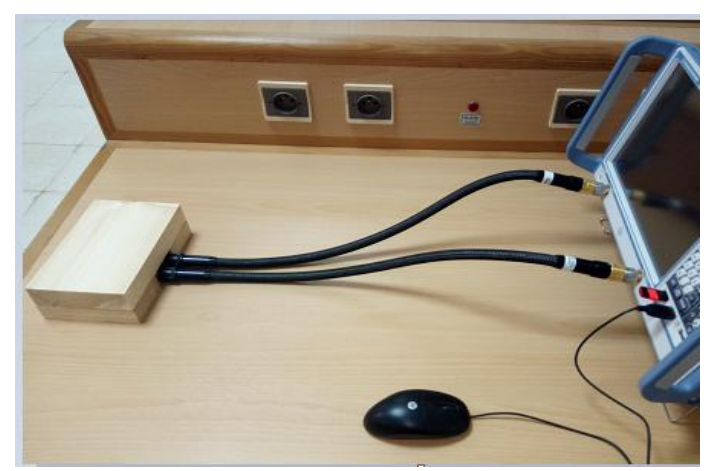

Figure 10: Reflection coefficients measurements of the MIMO antenna in contact condition with different building and decoration surfaces. 
Figure 12((a) and (b)) show that the Gypsum $\left(h_{g}\right)=127.7$ $\mathrm{mm}$ and the White Portland Cement $\left(h_{w p c}\right)=119.7 \mathrm{~mm}$ give nearly the same reflection coefficients appearances. As depicted in Figure 12((c), (d)), the Marble and Slate, that having thicknesses of around $90 \mathrm{~mm}$, have approximately the same reflection coefficients appearances. The Concrete, that is well-known as a high loss construction material, its reinforcement in thickness (from $21.48 \mathrm{~mm}$ to $85 \mathrm{~mm}$ ) and in Iron diameter (from $6 \mathrm{~mm}$ to $9 \mathrm{~mm}$ ) affect much more the wave and diminish the bandwidth of the two notchedbands, Figure 12((e), (f)). Furthermore, Figure 12((g) and (h)) indicate that the wood $\left(h_{w}\right)=180 \mathrm{~mm}$ has less influence on the wave compared with the Reinforced Concrete $\left(h_{r c}\right)=$ $85 \mathrm{~mm}$. As evident from the Figure 12 with comparing all the materials tested in this section a high penetration distance of the wave can be perceived by the wood $\left(h_{w}\right)=180 \mathrm{~mm}$. In addition, with all the construction and decoration materials examined in this section, the two bands corresponding to WiMaX and WLAN remain rejected and faintly affected by the change of the materials. As depicted in Table 1, several materials with thicker thickness are examined in this work compared to the materials tested in recent works.

(a)
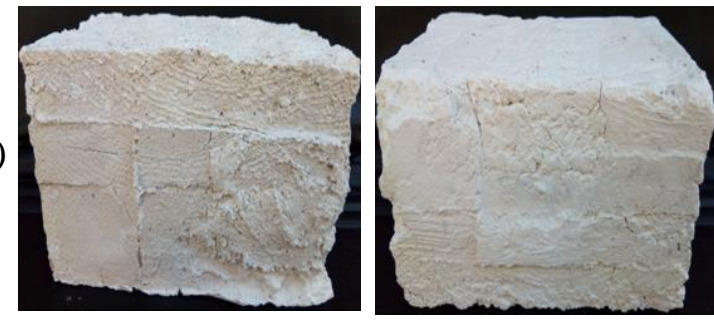

(b)

(c)
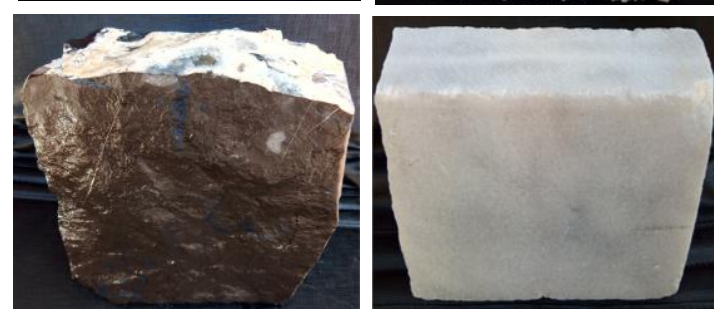

(d)

(e)
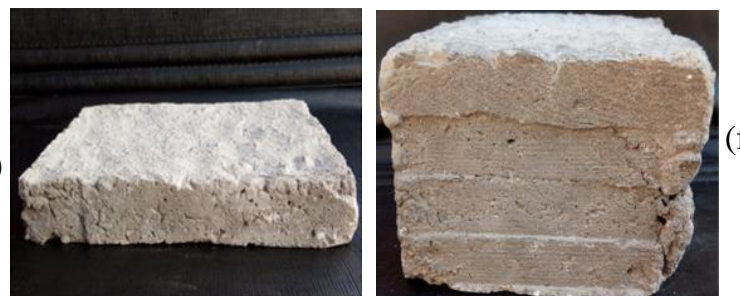

(g)

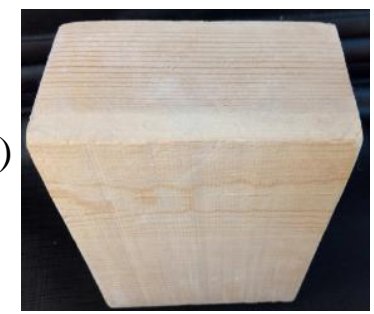

Figure 11: Types of surfaces used for the SP test, (a) Gypsum, (b) White Portland Cement, (c) Slate, (d) Marble, (e) Concrete, (f) Reinforced Concrete, (g) Wood.

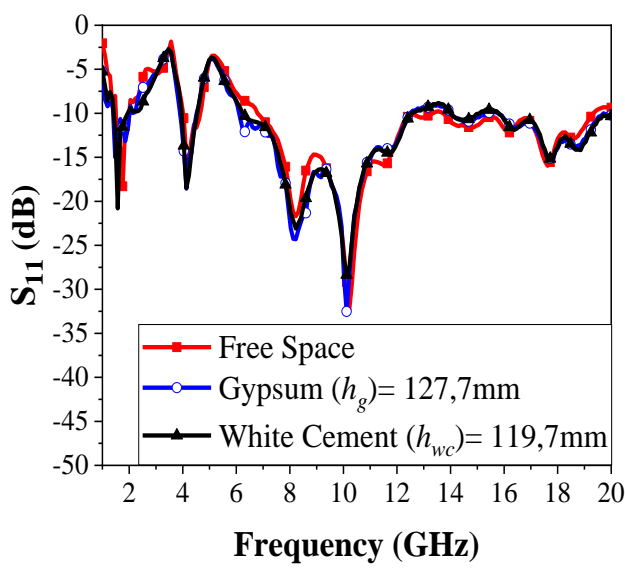

(a)

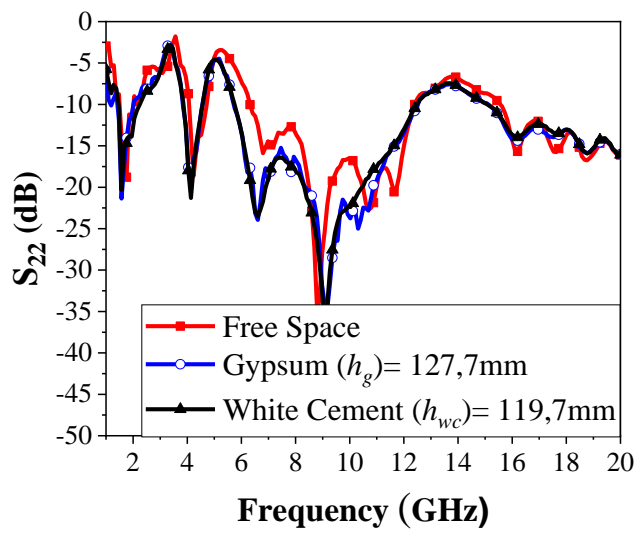

(b)

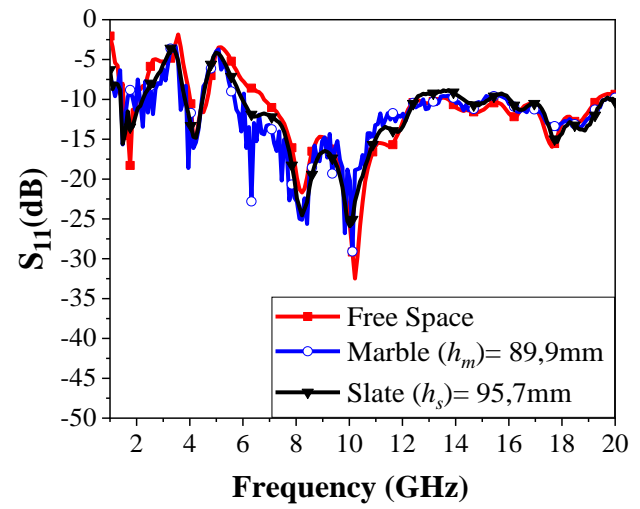

(c)

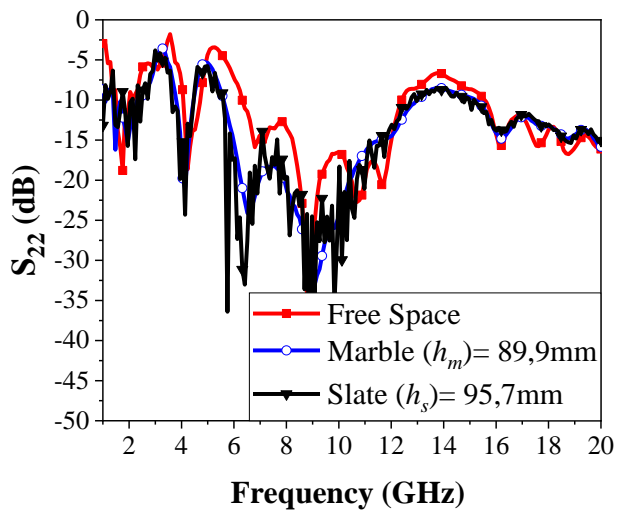

(d) 


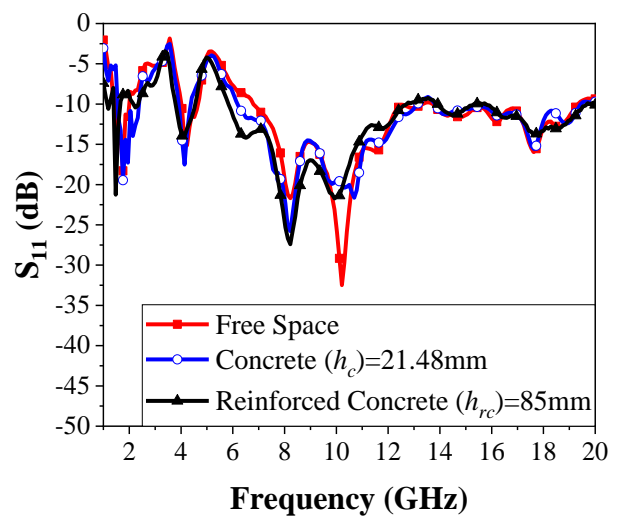

(e)

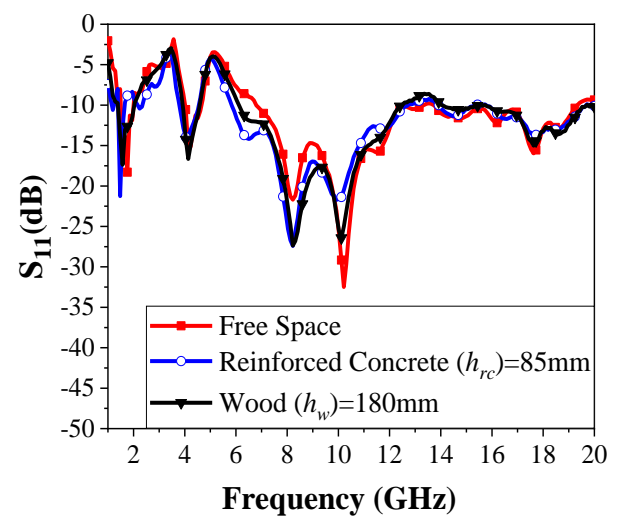

(g)

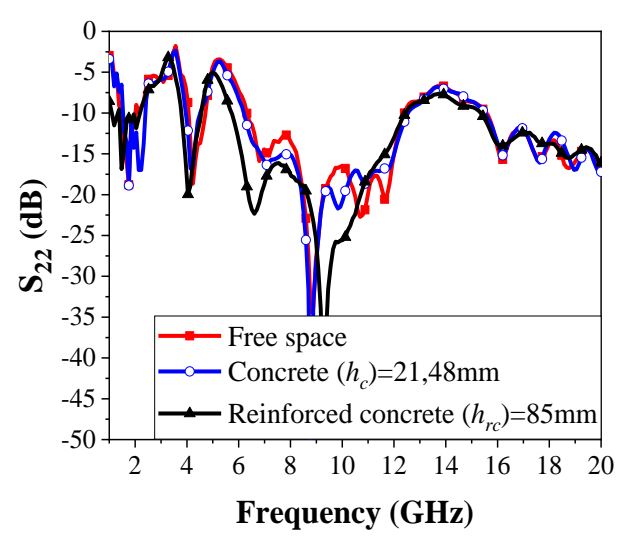

(f)

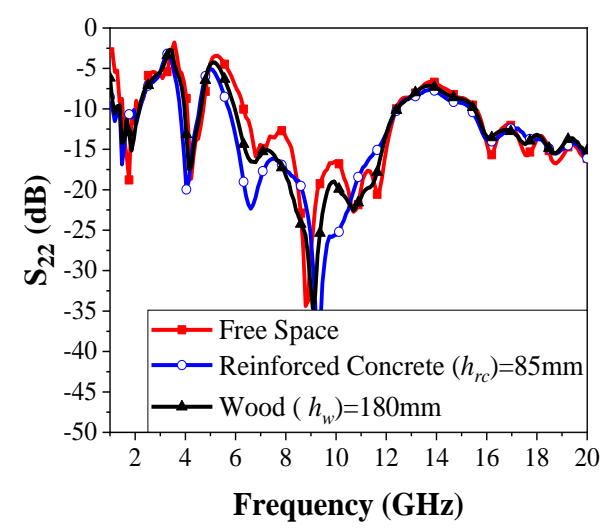

(h)

Figure 12: Measured reflection coefficients' comparison by the surfaces coupling.

Table 1: Measurements achieved in this work as a comparison with other recent works.

\begin{tabular}{|c|l|c|c|l|c|}
\hline Reference & Year & Bandwidth [GHz] & Notched bands & Examined materials & Thickness [mm] \\
\hline$[23]$ & 2017 & $3.1-13.1$ & No & Sandy Soil & 101.6 \\
\hline$[24]$ & 2018 & $2-14$ & No & Soil & 28 and 56 \\
\hline$[25]$ & 2018 & $2.58-11.62$ & Yes & Sand & 25.4 \\
& & & & Wood & 25.4 \\
\hline$[26]$ & 2018 & $3-20$ & No & Sand & 25.4 \\
& & & & Wood & 25.4 \\
\hline$[27]$ & 2018 & $3-14.64$ & No & Sand & 101.6 \\
\hline$[28]$ & 2018 & $1.75-10.3$ & Yes & Sand & 12.7 and 25.4 \\
\hline This work & 2018 & $1.57-12.4$ & Yes & Free space & 127.75 \\
& & & & Gypsum & 119.7 \\
& & & & White Cement & 95.7 \\
& & & & Slate & 89.9 \\
& & & & Marble & 180 \\
& & & & Wood & 85 \\
\hline
\end{tabular}

\section{Conclusions}

A compact printed coplanar waveguide fed UWB MIMO antenna with dual-band notched performance, for wireless communication systems with a high penetrating capability, has been successfully implemented and discussed. The dualband notched performance has been attained by introducing two symmetrical strips and three linked equal radius circles inside the radiating patches. The measured impedance 
bandwidth extends from $1.57 \mathrm{GHz}$ to $12.4 \mathrm{GHz}$ (155.05\%), covering the unlicensed UWB spectrum that ranges between $3.1 \mathrm{GHz}$ and $10.6 \mathrm{GHz}$ with two controlled notches from $2.04 \mathrm{GHz}$ to $3.94 \mathrm{GHz}$ and from $4.8 \mathrm{GHz}$ to $6.22 \mathrm{GHz}$. So, the antenna can avoid the interferences from co-existing systems. Surfaces penetrating test for the proposed MIMO antenna in touch condition of numerous construction and decoration materials has been achieved. With all the examined surfaces, the antenna preserves almost the same reflection coefficients appearances. An excellent penetrating capability is measured which proves the ability of the proposed antenna to work as SP antenna.

\section{References}

[1] S. Tripathi, A. Mohan, S. Yadav, A compact octagonal fractal UWB MIMO antenna with WLAN Bandrejection, Microwave Opt Technol Lett 57: 1919-1925, 2015.

[2] L. Wu, Y. Xia, X. Cao, Z. Xu, A miniaturized UWBMIMO antenna with quadruple band-notched characteristics, Int J Microw Wirel Technol 10: 948-955, 2018.

[3] S, Chouhan, D.K. Panda, V.S. Kushwah, Modified circular common element four-port multiple-inputmultiple-output antenna using diagonal parasitic element, Int J RF Microwave Comput Aid Eng e21527: 1-8, 2018.

[4] A. Sharma, A. Sarkar, A. Biswas, M.-J. Akhtar, Ashaped wideband dielectric resonator antenna for wireless communication systems and its MIMO implementation, Int J RF Microwave Comput Aid Eng e21402: 1-9, 2018.

[5] A.K. Gautam, S. Yadav, K. Rambabu, Design of ultracompact UWB antenna with band-notched characteristics for MIMO applications, Microwaves Antennas Propag IET 12: 1895-1900, 2018.

[6] S. Chouhan, D.K. Panda, M. Gupta, S. Singhal, Multiport MIMO antennas with mutual coupling reduction techniques for modern wireless transreceive operations: A review, Int J RF Microwave Comput Aid Eng 28: 1-13, 2017.

[7] E. Khoomwong, C. Phongcharoenpanich, Design of a dual-band bidirectional antenna using superellipsemonopole-fed rectangular ring for IEEE $802.11 \mathrm{a} / \mathrm{b} / \mathrm{g} / \mathrm{n}$ applications, Int J Antennas Propag ID 9368904: 1-11, 2016.

[8] C.R. Jetti, V.R. Nandanavanam, A very compact MIMO antenna with triple band-notch function for portable UWB systems. Progr Electromagn Res C 82: 13-27, 2018.

[9] A. Kumar, A.-Q. Ansari, B.-K. Kanaujia, J. Kishor, N. Tewari, Design of triple-band MIMO antenna with one band-notched characteristic. Progr Electromagn Res C 86: 41-53, 2018.

[10] Y. Dinesh, P.-A. Mahesh, K.-K. Shiban, T. Vivekanand, B. Deepak, Two element band-notched UWB MIMO antenna with high and uniform isolation, Progr Electromagn Res M 63: 119-129, 2018.

[11] W. Wenjing, Y. Bo, W. Aiting, A quad-element UWBMIMO antenna with band-notch and reduced mutual coupling based on EBG structures, Int J Antennas Propag: Article ID 8490740: 1-10, 2018.

[12] N. Malekpour, M.-A. Honarvar, A. Dadgarpur, B.-S. Virdee, T.-A. Denidni, Compact UWB MIMO antenna with band-notched characteristic, Microwave Opt Technol Lett 59: 1037-1041, 2017.

[13] S. Rajkumar, K.-T. Selvan, P.-H. Rao, Compact 4 element Sierpinski Knopp fractal UWB MIMO antenna with dual band notch, Microwave Opt Technol Lett 60: 1023-1030, 2018.

[14] L. Guifeng, L. Ying, G. Shuxi, Compact uniplanar UWB MIMO antenna with band-notched characteristic, Microwave Opt Technol Lett 59: 2207-2212, 2017.

[15] R. Nayak, S. Maiti, A review of Bow-Tie antennas for GPR applications, IETE Tech Rev, 1-16, 2018.

[16] D.-M. Elsheakh, E.-A. Abdallah, Compact printed logperiodic dipole antenna for water detection by using ground penetrating radar, Microwave Opt Technol Lett 56: $1225-1232,2014$

[17] C. Warren, A. Giannopoulos, Characterisation of a ground penetrating radar antenna in lossless homogeneous and lossy heterogeneous environments, Signal Processing 132: 221-226, 2017.

[18] F. Zhang, G.-Y, Fang, Y.-C. Ji, H.-J. Ju, J.-J. Shao, A novel compact double exponentially tapered slot antenna (DETSA) for GPR applications, IEEE Antennas Wirel Propag Lett 10: 195-198, 2011.

[19] M. Li, R. Birken, N.-X. Sun, M.-L. Wang, Compact slot antenna with low dispersion for ground penetrating radar application, IEEE Antennas Wirel Propag Lett 15: $638-641,2015$.

[20] W. Bingheng, J. Yicai, F. Guangyou, Analysis of GPR UWB half-ellipse antennas with different heights of backed cavity above ground, IEEE Antennas Wirel Propag Lett 9: 130-133, 2010.

[21] M. Moosazadeh, S. Kharkovsky, J.T. Case, B. Samali, Miniaturized UWB antipodal vivaldi antenna and its application for detection of void inside concrete specimens, IEEE Antennas Wirel Propag Lett 16: 1317 1320, 2016.

[22] S. Jinjin, F. Guangyou, F. Jingjing, J. YiCai, Y. Hejun, TEM horn antenna loaded with absorbing material for GPR applications, IEEE Antennas Wirel Propag Lett 13: 523 - 527, 2014.

[23] S. Kundu, S.K. Jana, A compact umbrella shaped UWB antenna for ground coupling GPR applications, Microwave Opt Technol Lett 60:146 -151, 2017.

[24] S. Kundu, S.K. Jana, A leaf shaped CPW-fed UWB antenna for GPR applications, Microwave Opt Technol Lett 60: 941-945, 2018.

[25] S. Kundu, S.K. Jana, Leaf-shaped CPW-fed UWB antenna with triple notch bands for ground penetrating radar applications, Microwave Opt Technol Lett 60: 930936, 2018.

[26] S. Kundu, Experimental study of CPW-fed printed UWB antenna with radiation improvement for ground coupling GPR application, Microwave Opt Technol Lett 60: 2462-2464, 2018. 
[27] S. Kundu, A. Chatterjee, S.K. Jana, S.K. Parui, Gain enhancement of a printed leaf shaped UWB antenna using dual FSS layers and experimental study for ground coupling GPR applications, Microwave Opt Technol Lett 60: 1417-1423, 2018.

[28] S. Kundu, A. Chatterjee, S.K. Jana, S.K. Parui, A high gain dual notch compact UWB antenna with minimal dispersion for ground penetrating radar application, Radioengineering 27: 990-997, 2018.

[29] CST Microwave Studio, Computer Simulation Technology (CST) version 2016, Germany. Available at: https://www.cst.com/Products/CSTMWS. 2016.

[30] T. Arshed, F.A. Tahir, A miniaturized triple bandnotched UWB antenna. Microwave Opt Technol Lett 59: 2581-2586, 2017.

[31] R. Chandel, A.-K. Gautam, K. Rambabu, Tapered fed compact UWB MIMO-diversity antenna with dual bandnotched characteristics, IEEE Trans Antenna Propag 66 : 1677-1684, 2018.

[32] L. Kang, H. Li, X. Wang, X. Shi, Compact offset microstrip-fed MIMO antenna for band-notched UWB applications, IEEE Antennas Wirel Propag Lett 14: 1754-1757, 2015.

[33] L. Wu, Y. Xia, Compact UWB-MIMO antenna with quadband notched characteristic, Int J Microw Wirel T 9: 1147-1153, 2017.

[34] G. Srivastava, B.-K. Kanuijia, Compact dual bandnotched UWB MIMO antenna with shared radiator, Microwave Opt Technol Lett 57: 2886-2891, 2015.

[35] L. Malviya, R. K. Panigrahi and M. V. Kartikeyan, MIMO antennas with diversity and mutual coupling reduction techniques: a review, Int J Microw Wirel Technol 9 : 1763-1780, 2017. 